CLINICAL STUDY

\title{
Novel mutations of the thyroid peroxidase gene in patients with permanent congenital hypothyroidism
}

\author{
Petra Ambrugger, Iva Stoeva ${ }^{1}$, Heike Biebermann, Toni Torresani ${ }^{3}$, Christa Leitner ${ }^{2}$ and Annette Grüters \\ Otto Heubner Zentrum für Kinder- und Jugendmedizin, Pädiatrische Endokrinologie, CVK, Humboldt University, Berlin, Germany, ${ }^{1}$ University Children's \\ Hospital, Medical Faculty, Sofia, Bulgaria, ${ }^{2} J$ W Goethe University, Frankfurt/Main, Germany and ${ }^{3}$ University Children's Hospital, Kinderspital, \\ Zürich, Switzerland \\ (Correspondence should be addressed to A Grüters, Otto Heubner Zentrum für Kinder- und Jugendmedizin, Pädiatrische Endokrinologie, CVK, Humboldt- \\ Universität zu Berlin, Augustenburger Platz 1, 13353 Berlin; Email: annette.grueters@charite.de)
}

\begin{abstract}
Objective: It is suggested that iodide organification defects account for $10 \%$ of all cases with congenital hypothyroidism $(\mathrm{CH})$. One candidate gene for these defects is the thyroid peroxidase (TPO) gene. Design: Exons 2, 8-10 and 14 of the TPO gene were examined in 30 patients with permanent $\mathrm{CH}$ without a family history of $\mathrm{CH}$. This group was characterized by the presence of an orthotopic thyroid gland and elevated TSH levels.

Methods: The mutational screening was performed by single-strand conformational polymorphism followed by sequence analysis of fragments with abnormal migration patterns and by restriction enzyme analysis.

Results: In four patients we were able to identify mutations on both alleles which have not been described so far. One patient was a carrier of a new homozygous point mutation in exon 9 resulting in an exchange from Leu to Pro at codon 458. Another patient was found to be compound heterozygous for two mutations, a 20 bp duplication in exon 2 and a new mutation in exon 9 (Arg491His). Two brothers of consanguineous parents showed a homozygous T deletion in exon 14 at position 2512 . Conclusions: Our findings confirm the genetic heterogeneity of TPO defects and support the suggested prevalence of organification defects.
\end{abstract}

European Journal of Endocrinology 145 19-24

\section{Introduction}

Primary congenital hypothyroidism $(\mathrm{CH})$ is one of the most common endocrine disorders in childhood. According to morphological findings the disease can be subdivided into defects of thyroid development (dysgenesis), ranging from hypoplasia to athyrosis, and into defects of thyroid hormone biosynthesis (1). Eighty percent of all cases are defined as thyroid dysgenesis. Only in very few cases of thyroid dysgenesis has the molecular basis been clarified, for example mutations of the thyroid-stimulating hormone (TSH) receptor gene (2-4) and of transcription factors PAX-8 (5), TTF-1 (6) and TTF-2 (7). Only 10-20\% of all cases are assumed to be due to defects in thyroid biosynthesis. The genetic background for these defects is well accepted. Candidate genes are the sodium iodide symporter $(8,9)$, the thyroglobulin $(\mathrm{Tg})$ gene $(10,11)$, the pendrin gene $(12,13)$ and the thyroid peroxidase (TPO) gene (14-16). TPO is a hemoprotein responsible for tyrosine iodination and coupling. So far 18 mutations in ten exons have been described (17-19). Most missense mutations are located in the catalytic center of the enzyme encoded by exons 8-10. Furthermore, the recently reported thyroid follicular carcinoma in a newborn with a heterozygous mutation in exon 14 of the TPO gene (20), and follicular adenoma in a patient with compound heterozygous mutations in exons 7 and 14 (18), have focused attention on the importance of a molecular genetic diagnosis in patients with $\mathrm{CH}$, because regular ultrasound investigation of the thyroid gland is probably warranted in patients with proven defects of TPO.

\section{Subjects and methods}

\section{Patients}

A mutational screening was performed in 30 patients with $\mathrm{CH}$ from 25 different, unrelated families. In five of the patients a sibling was affected by $\mathrm{CH}$, but in none of the families had a case of $\mathrm{CH}$ been reported in a previous generation. The diagnosis was made after an elevated TSH level was measured in the filter-paper card with an immunofluorometric assay (Delfia; Wallac, Turku, Finland; cut off $>15-\mathrm{mU} / \mathrm{l}$, blood sampling on 
days 3-5 of life) and by confirmation of elevated serum TSH levels (Delfia; Wallac) and decreased serum thyroxine $\left(\mathrm{T}_{4}\right)$ levels (Delfia; Wallac) (Table 1). After 2 years of treatment with L-thyroxine, therapy withdrawal was introduced for 4 weeks and the children were reinvestigated by determination of $\mathrm{TSH}, \mathrm{T}_{4}$ and $\mathrm{Tg}$ measured in serum with an IRMA (Brahms Diagnostica, Henningsdorf, Germany). Thyroid ultrasound was performed in order to ensure the presence of an orthotopic thyroid gland.

To investigate whether a detected mutation was a common polymorphism, an additional 100 healthy control persons as well as 100 patients with $\mathrm{CH}$ and thyroid dysgenesis were investigated.

\section{Genomic analysis}

Genomic DNA was extracted from peripheral white blood cells using a commercial kit (Qiagen, Hilden, Germany) according to the manufacturer's protocol. The human TPO gene was amplified by PCR. Primers were selected as reported by Bikker et al. (15). The PCR was performed in $50 \mu \mathrm{l}$ reactions for 30 cycles by using AmpliTaq Polymerase (Perkin Elmer, Weiterstadt, Germany). Single-strand conformational polymorphism (SSCP) analysis was carried out in exons 2, 8-10 and 14 as described by Orita et al. (21). To identify the GGCC duplication in exon 8 , PCR products were further characterized by restriction endonuclease digestion with NaeI (14) followed by separation on $2 \%$ agarose gels. Furthermore, restriction analysis was performed for exon 2 with the enzyme BsrI (22) and for the homozygous mutation in exon 9 with MspI. In patients with an abnormal electrophoretic mobility pattern in the SSCP, dideoxy sequencing (23) was performed with a BigDye Terminator Cycle Sequencing Ready Reaction Kit (Perkin Elmer). The sequencing reactions were analyzed with an automatic sequencer (ABI 377; Applied Biosystems, Foster City, CA, USA). The numbering of mutations corresponds to that of Kimura \& Ikeda-Saito (24).

\section{Results}

We were able to detect mutations on both alleles of the TPO gene in 4 out of 30 patients. These four patients belonged to three unrelated families.

\section{Patient 1}

At final diagnosis (14 weeks), patient 1 showed strikingly elevated TSH levels and an almost unmeasurable value for $\mathrm{T}_{4}$ (Table 1 ). At the age of 16 years, an ultrasound investigation of the patient's thyroid gland showed two nodules in the left and one nodule in the right lobe. All three nodules had an inhomogenic echo structure and showed augmented vascularization in Doppler ultrasonography. At that time the serum $\mathrm{Tg}$ level was markedly elevated $(558 \mathrm{ng} / \mathrm{ml})$. The mother of the patient had had a goiter since childhood and is receiving L-thyroxine therapy.

SSCP analysis of family 1 revealed both parents as heterozygous carriers of an abnormal electrophoretic mobility pattern in exon 9 whereas the affected daughter was a homozygous carrier of the aberrant DNA variant (Fig. 1B). Subsequently sequence analysis indicated a missense mutation at position 1463 with a nucleotide change from $\mathrm{T}$ to $\mathrm{C}$, resulting in an amino acid exchange from Leu to Pro at codon 458 (Fig. 1C). The mutation creates a new restriction site for MspI in this PCR fragment. In the homozygous state of this mutation, the $298 \mathrm{bp}$ fragment was completely digested whereas in the heterozygous state only one allele is cut and the other remains undigested (Fig. 1D).

\section{Patient 2}

At the time of final diagnosis (4 months), the TSH level of patient 2 was significantly elevated (Table 1 ). The thyroid gland was of normal size, structure and position. The patient's mother had a small goiter and a serum $\mathrm{Tg}$ level higher than $360 \mathrm{ng} / \mathrm{ml}$. No other family member was known to have a thyroid disorder.

In the patient, SSCP analysis showed an abnormal electrophoretic mobility pattern in exon 9 and exon 2 of the TPO gene compared with the PCR product of controls. Further investigation of the TPO gene of the parents revealed that the father was a carrier of the same heterozygous abnormality in exon 9 , whereas in the mother an abnormal heterozygous mobility pattern of exon 2 was detected (Fig. 2A). Sequence analysis disclosed the father as the heterozygous carrier of a mutation in exon 9. This $\mathrm{G}$ to A transition results in an

Table 1 Hormonal and clinical data (at diagnosis) of the patients with mutations on both alleles of the TPO gene.

\begin{tabular}{|c|c|c|c|c|c|c|}
\hline Patient no. & Sex & Thyroid gland & $\begin{array}{l}\text { TSH } \\
(\mathrm{mU} / \mathrm{l})\end{array}$ & $\begin{array}{c}\mathbf{T}_{\mathbf{4}} \\
(\mathrm{nmol} / \mathrm{l})\end{array}$ & $\begin{array}{c}\mathbf{T g}^{*} \\
(\mathrm{ng} / \mathrm{ml})\end{array}$ & $\begin{array}{c}\mathrm{TG}^{* *} \\
(\mathrm{ng} / \mathrm{ml})\end{array}$ \\
\hline 1 & $\mathrm{~F}$ & Cystic degeneration & $>80$ & $<13$ & ND & 103 \\
\hline 2 & $\mathrm{~F}$ & Normal in size and structure & 160 & - $^{\star \star \star}$ & ND & 371 \\
\hline 3 & M & Goiter development under therapy & 345 & 16 & $>1000$ & ND \\
\hline 4 & M & Normal in size and structure & 482 & 31 & 499 & ND \\
\hline Normal values & - & - & $<10$ & $105-240$ & $10-110$ & $2-65$ \\
\hline
\end{tabular}

ND: not done; ${ }^{*} \mathrm{Tg}$ levels at time of diagnosis (1 week); ${ }^{\star \star} \mathrm{Tg}$ levels at withdrawal; ${ }^{\star \star \star}$ reported as below normal. 


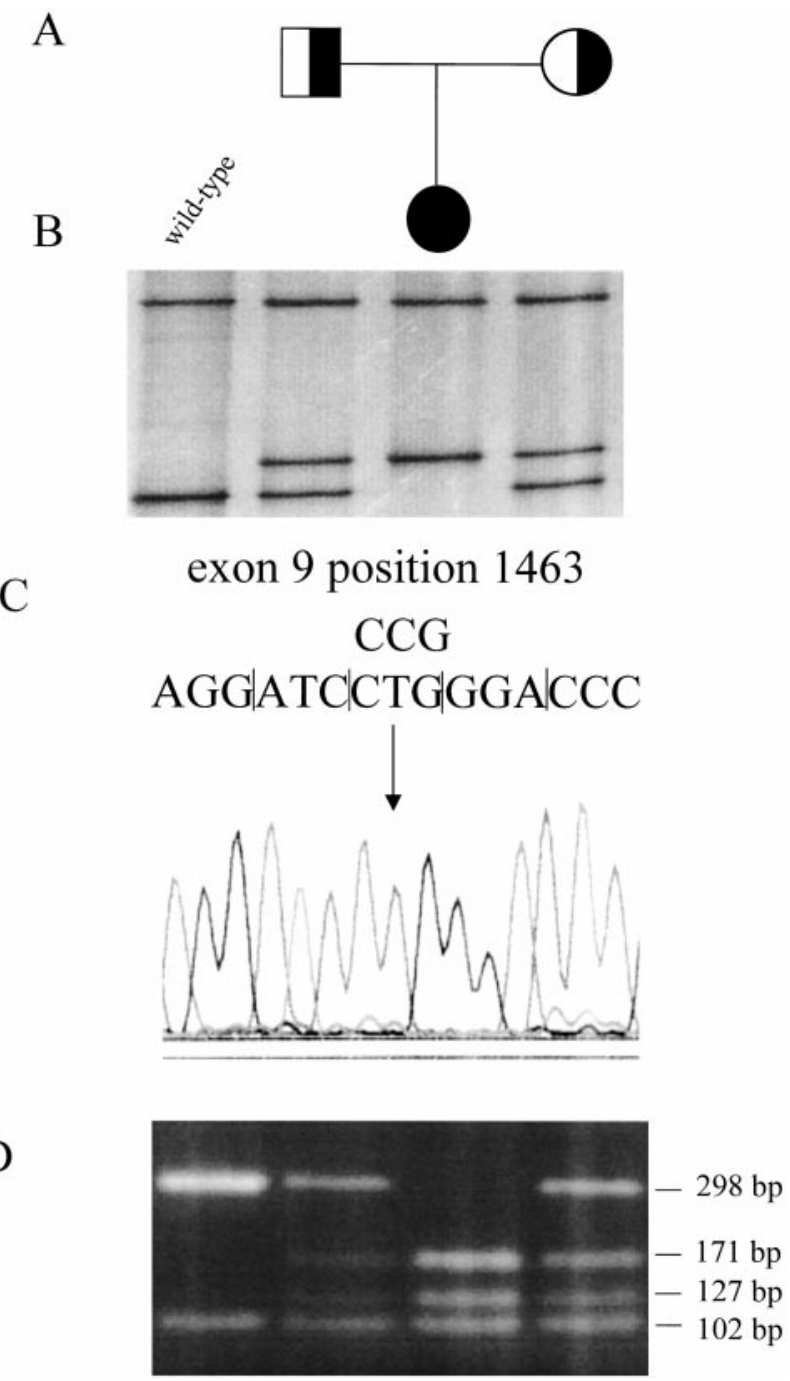

Figure 1 Homozygous missense mutation in exon 9 of patient 1. (A) The pedigree of the affected family is aligned with the SSCP (B) and restriction enzyme analysis (D). Heterozygotes are shown by half-filled symbols, homozygotes by filled symbols. (B) SSCP analysis reveals an homozygous abnormal electrophoretic mobility pattern of the patient's PCR fragment compared with that of wild-type. The parent's PCR fragments show a heterozygous divergence from the wild-type DNA. (C) Sequence analysis of exon 9 shows a mutation at position 1463 resulting in a nucleotide change from $\mathrm{T}$ to $\mathrm{C}$. The wild-type sequence is on the bottom. The arrow indicates the missense mutation. (D) Restriction enzyme analysis of the family's PCR product of exon 9 was performed with Mspl. The fragments were separated on a $2 \%$ agarose gel. Numbers on the right show the length of the restricted base pairs. The PCR product of a control person is cut once and produces two fragments of 298 and $102 \mathrm{bp}$. The heterozygous mutation creates a new restriction site which is demonstrated by two further fragments with a length of 171 and $127 \mathrm{bp}$. In the homozygous state of this mutation the $298 \mathrm{bp}$ band is completely digested.

exchange from Arg to His at codon 491. The mother is a heterozygous carrier of the already described $20 \mathrm{bp}$ duplication in exon 2 of the TPO gene. This mutation leads to a frameshift with an early stop codon in exon 3
(Fig. 2B). The patient is compound heterozygous for the two detected abnormalities in the TPO gene.

\section{Patients 3 and 4}

Patients 3 and 4 both showed elevated TSH and Tg levels as well as diminished $\mathrm{T}_{4}$ values at time of diagnosis (Table 1). In addition, patient 3 developed a goiter, possibly due to irregular supplementation of thyroid hormones. The consanguineous parents and a healthy sister had euthyroid hormone levels.

Analysis of the TPO gene in the family with PCRSSCP revealed a conspicuous mobility pattern in exon 14. The migrational behavior of the parents' PCR products implicates a heterozygous variant, whereas the PCR fragments of both sons showed a homozygous abnormality. The mobility pattern of the daughter's PCR fragment is comparable with that of an unrelated control person (Fig. 3A). A subsequent sequencing analysis showed a homozygous $\mathrm{T}$ deletion at position 2512 apparent in both sons. The parents are heterozygous carriers of this frameshift mutation leading to a premature stop in exon 14 of the TPO gene.

\section{Screening for the new mutations in exon 9}

In an additional screening of 100 healthy control persons and 100 patients with $\mathrm{CH}$ and thyroid dysgenesis, neither of the new mutations in exon 9 (Leu458Pro, patient 1 and Arg491His, patient 2) was detected.

\section{Discussion}

This group of 30 patients with sporadic permanent $\mathrm{CH}$ is one of the largest studied for mutations in the TPO gene. In four of the patients we could detect mutations on both alleles.

The novel homozygous mutation in exon 9 (Leu458Pro) described in patient 1 is located before the proximal His. Like amino acids Ile 447, Tyr 453 and Gly 590 (25), Leu 458 is located in a conserved part of TPO. Due to its aliphatic side chain, Leu takes a decisive part in the creation of hydrophobic links and may be important in the formation of the tertiary structure. The substitution of Leu with Pro interrupts the $\alpha$-helical structure in a fashion such that after the peptide link hydrogen bridges can probably not be formed any more. Therefore, the structure and substrate-binding capabilities of the TPO molecule are thought to be heavily affected.

The new mutation in exon 9 in patient 2 was found compound heterozygous with the known 20 bp duplication in exon 2 (22). The novel mutation in exon 9 is an amino acid substitution at position 1562 (Arg491His), which is located close to the proximal His and can probably affect the heme binding. Kimura \& Ikeda-Saito (24) suggested that in TPO the proximal 
A

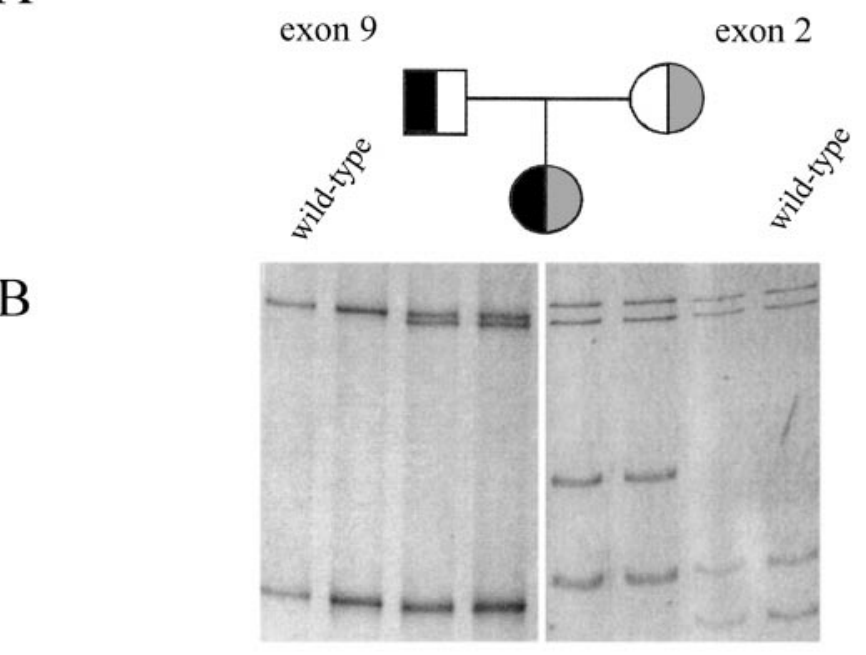

C

exon 9

position 1562

CAC

T TClCGC|TTC|G G

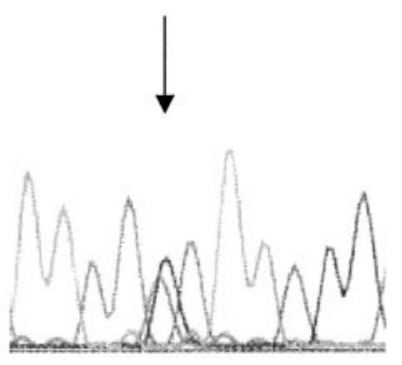

exon 2

position 141

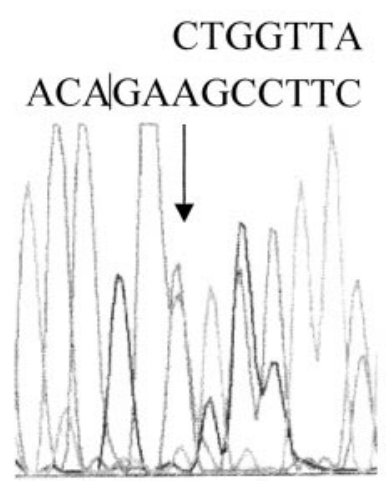

Figure 2 Compound heterozygous mutation in exons 9 and 2 of patient 2 . (A) Pedigree of the family is shown in line with SSCP analysis (B) and sequence analysis (C). Heterozygotes are defined by half-filled symbols. The compound heterozygous mutation is shown by the filled symbol, which stands for both mutations. (B) The SSCP analysis demonstrates two different heterozygous mutations; one in exon 9 and the other in exon 2. The patient carries both mutations whereas the father is a carrier of the mutation in exon 9 and the mother is carrying the mutation in exon 2. (C) Sequence analysis shows the nucleotide change from $G$ to $A$ in exon 9 (left side) and the frameshift in exon 2 (right side). The arrows indicate the mutations.
His, linked to the iron center of the heme, is located at residue 407 . X-ray crystallography of myeloperoxidase showed clearly that His336 is more likely to act as proximal His (26) and the corresponding His in TPO is located at position 494 in exon 9. The G to A transition leads to an exchange from Arg to His and results in the appearance of a fourth His with possible influences on the proper binding of the iron center of the heme. However, functional studies are needed to examine this theoretical suggestion. It is interesting to follow this mutation because of the critical importance of this region for fully active TPO. There are no other known mutations located so close to the proximal His 494. The combination of this mutation with a frameshift mutation in exon 2 suggests that both alleles give rise to an almost inactive enzyme.

The finding of these two novel mutations supports once more the importance of exon 9 for the proper structure and function of the TPO enzyme. The absence of both mutations in a survey population of 200 individuals underlines that the mutations detected in exon 9 of the TPO gene are causally related to the phenotype of our patients. This is of particular interest for the homozygous mutation Leu458Pro, which is found in a patient with a cystic degeneration of the thyroid gland. The rapid increase in size of the thyroid gland during 4 weeks of therapy withdrawal points to the presence of a total iodide organification defect. To confirm this, functional studies are of major importance.

Exon 14 takes part in the coding of the membranespanning part of TPO. The sequence of the C-terminal exons $13-17$ is highly conserved in TPO. Mutations found in exon 14 were functionally investigated and were shown to lead to an enzymatically inactive TPO (25). This suggests that this region of the protein is important for proper folding and serves not only as a hinge for insertion of the membrane. Recently a new mutation was reported by Bakker et al. (19): a 


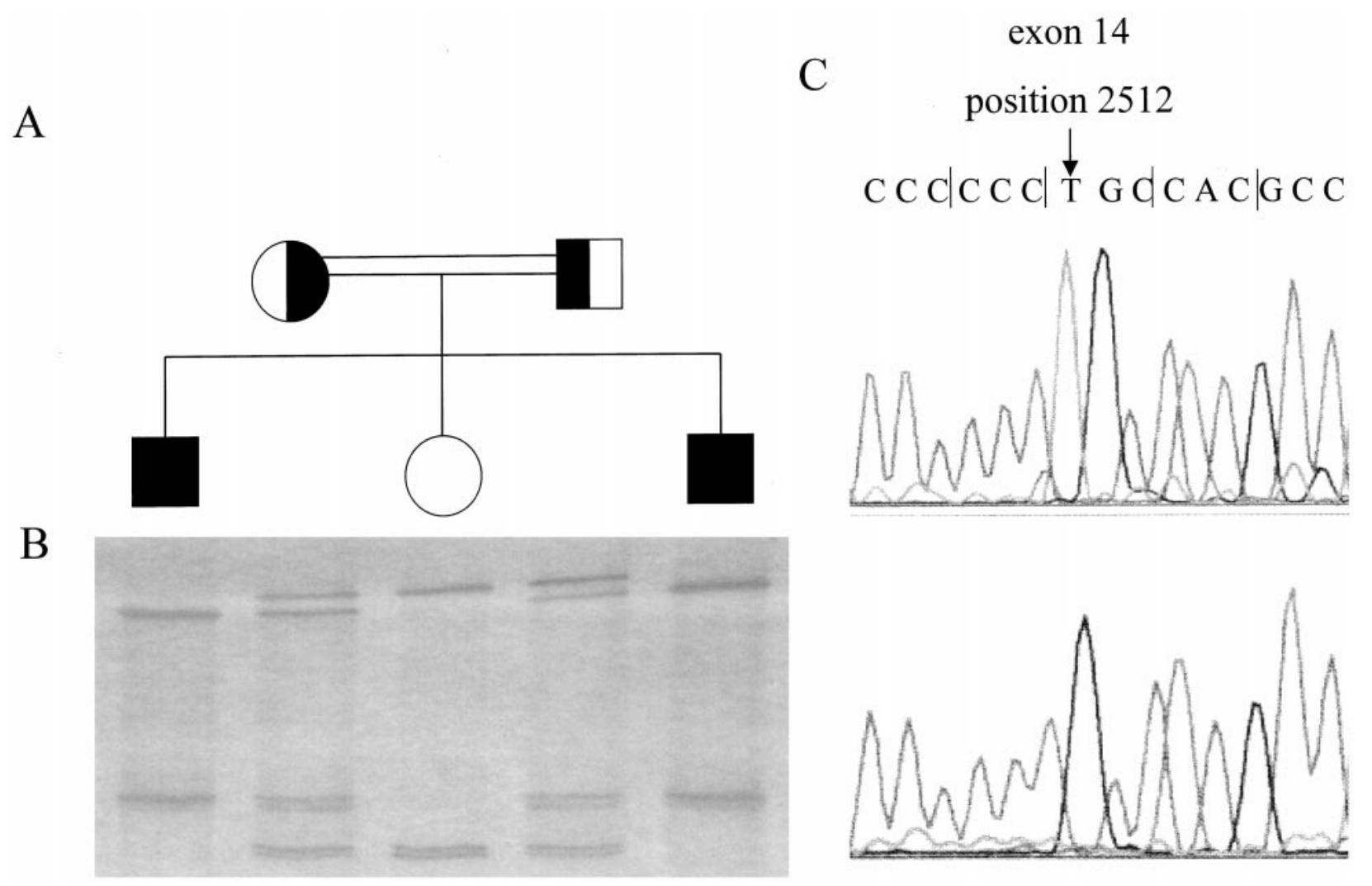

Figure 3 Homozygous T deletion in exon 14 of patients 3 and 4. (A) Pedigree of family 3 . Heterozygotes are shown by half-filled and affected patients by filled symbols. (B) SSCP analysis, which indicates both patients as homozygous carriers of the mutation whereas both parents carry the mutation in a heterozygous state. The daughter is not a carrier of the mutation. (C) Sequence analysis showing the wild-type DNA sequence of the daughter on top. Thereunder the homozygous T deletion at position 2512 of both patients is demonstrated. The arrow indicates the mutation.

$\mathrm{T}$ deletion at position 2512 as the result of maternal uniparental disomy. This mutation causes a frameshift leading to an early termination signal in exon 14 . Two patients in this study showed the same mutation in a homozygous state inherited from the mother and father who are both heterozygous; again, the Tg levels were extremely elevated. A goiter was evident only in one patient, possibly due to an irregular supplementation of thyroid hormone. The region between 2505 and 2512 in exon 14 seems to be a frequent target for alterations. Recently Kotani et al. (18) and Medeiros-Neto et al. (20) reported patients with a $C$ insertion at position 2511 and a follicular adenoma and a follicular carcinoma respectively. The newborn with a follicular carcinoma showed evidence of a large neck mass and despite surgery on the 7th day of life was found to have early metastases in the lung and bones. The second mutation in the TPO gene was not found. The father and paternal grandmother (the latter also suffering from thyroid carcinoma) were heterozygous for the same mutation. Intimate molecular mechanisms for the tumor development in this family and its rapid progression are still unknown.
The increasing number of patients with genotyping will provide data on the intriguing role of TPO mutations in the development of thyroid tumor. Therefore it has to be concluded that genotyping of the TPO gene in patients with $\mathrm{CH}$ and assumed defects of thyroid biosynthesis should not only be performed in order to provide genetic counseling, but also to recommend regular ultrasound investigation in these patients during L-thyroxine replacement.

\section{Acknowledgements}

The authors would like to thank the DAAD and Sonnenfeld-Stiftung for financial support and Katrin Huhne for excellent technical assistance.

\section{References}

1 Grüters A. Congenital hypothyroidism. Pediatric Annals 199221 $15-21$.

2 Abramowicz MJ, Duprez L, Parma J, Vassart G \& Heinrichs C. Familial congenital hypothyroidism due to inactivating mutation of the thyrotropin receptor causing profound hypoplasia of 
the thyroid gland. Journal of Clinical Investigation 199799 3018-3024.

3 Biebermann H, Schöneberg T, Krude H, Schultz G, Gudermann T \& Grüters A. Mutations of the human thyrotropin receptor gene causing thyroid hypoplasia and persistent congenital hypothyroidism. Journal of Clinical Endocrinology and Metabolism 199782 3471-3480.

4 Gagné N, Parma J, Deal C, Vassart G \& Van Vliet G. Apparent congenital athyreosis contrasting with normal plasma levels and associated with inactivating mutations in the thyrotropin receptor gene: are athyreosis and ectopic thyroid distinct entities?. Journal of Clinical Endocrinology and Metabolism 1998 83 1771-1775.

5 Macchia PE, Lapi P, Krude H, Pirro MT, Missero C, Chiovato L et al. PAX8 mutations associated with congenital hypothyroidism caused by thyroid dysgenesis. Nature Genetics 199819 83-86.

6 De Vriendt K, Vanhole C, Matthijs G \& de Zegher F. Deletion of thyroid transcription factor-1 gene in an infant with neonatal thyroid dysfunction and respiratory failure. New England Journal of Medicine 1998338 1317-1318.

7 Clifton-Bligh RJ, Wentworth JM, Heinz P, Crisp MS, John R, Lazarus JH et al. Mutation of the gene encoding human TTF-2 associated with thyroid agenesis, cleft palate and choanal atresia. Nature Genetics 199819 399-401.

8 Fujiwara H, Tatsumi K, Miki K, Harada T, Okada S, Nose O et al. Recurrent T354P mutation of the $\mathrm{Na}^{+} / \mathrm{I}^{-}$symporter in patients with iodide transport defect. Journal of Clinical Endocrinology and Metabolism 199883 2940-3000.

9 Pohlenz J, Medeiros-Neto G, Gross JL, Silveiro SP, Knobel M \& Refetoff S. Hypothyroidism in a Brazilian kindred due to iodide trapping defect caused by a homozygous mutation in the sodium/ iodide symporter gene. Biochemical and Biophysical Research Communications $1997240488-491$.

10 Ieiri T, Cochaux P, Targovnik HM, Suzuki M, Shimoda S, Perret J et al. A $3^{\prime}$ splice site mutation in the thyroglobulin gene responsible for congenital goiter with hypothyroidism. Journal of Clinical Investigation $1991 \mathbf{8 8}$ 1901-1905.

11 Van de Graaf SA, Cammenga M, Ponne NJ, Veenboer GJ, Gons $\mathrm{MH}$, Orgiazzi $\mathrm{J}$ et al. The screening for mutations in the thyroglobulin cDNA from six patients with congenital hypothyroidism. Biochimie 199981 425-432.

12 Everett LA, Glaser B, Beck JC, Idol JR, Buchs A, Heyman M et al. Pendred syndrome is caused by mutations in a putative sulphate transporter gene (PDS). Nature Genetics $1997 \mathbf{1 7}$ 411-422.

13 Coyle B, Reardon W, Herbrick JA, Tsui LC, Gausden E, Lee J et al. Molecular analysis of the PDS gene in Pendred syndrome. Human Molecular Genetics 19987 1105-1112.

14 Abramowicz MJ, Targovnik HM, Varela V, Cochaux P, Krawiec L, Pisarev MA et al. Identification of a mutation in the coding sequence of the human thyroid peroxidase gene causing congenital goiter. Clinical Investigation 199290 1200-1204.
15 Bikker H, Vulsma T, Baas V \& de Vijlder JJM. Identification of five novel inactivating mutations in the human thyroid peroxidase gene by denaturating gradient gel electrophoresis. Human Mutation 19956 9-16.

16 Bikker H, Waelkens JJ, Bravenboer B \& de Vijlder JJ. Congenital hypothyroidism caused by a premature termination signal in exon 10 of the human thyroid peroxidase gene. Journal of Clinical Endocrinology and Metabolism 199681 2076-2079.

17 Santos CL, Bikker H, Rego KG, Nascimento AC, Tambascia M, de Vijlder JJ et al. A novel mutation in the TPO gene in goitrous hypothyroid patients with iodide organification defect. Clinical Endocrinology 199951 165-172.

18 Kotani T, Umeki K, Yamamoto I, Maeseka H, Tachibana K \& Ohtaki S. A novel mutation in the human thyroid peroxidase gene resulting in a total iodide organification defect. Journal of Endocrinology $1999160267-273$.

19 Bakker B, Bikker H, Vulsma T, de Randamie JS, Wiedijk BM \& de Vijlder JJ. Two decades of screening for congenital hypothyroidism in the Netherlands: TPO gene mutations in total iodide organification defects. Journal of Clinical Endocrinology and Metabolism 200085 3708-3712.

20 Medeiros-Neto G, Gil-Da Costa MJ, Santos C, Medina AM, Silvia JC, Tsou RM et al. Metastatic thyroid carcinoma arising from congenital goiter due to mutation in the thyroperoxidase gene. Journal of Clinical Endocrinology and Metabolism 19983 $4162-4166$.

21 Orita M, Suzuki Y, Sekiya T \& Hayashi K. Rapid and sensitive detection of point mutations and DNA polymorphisms using the polymerase chain reaction. Genomics $19895874-879$.

22 Bikker H, den Hartog MT, Baas F, Gons MH, Vulsma T \& de Vijlder JJM. 20-basepair duplication in the human thyroid peroxidase gene results in a total iodide organification defect and congenital hypothyroidism. Journal of Clinical Endocrinology and Metabolism 199479 248-252.

23 Sanger F, Nicklen S \& Coulson AR. DNA sequencing with chainterminating inhibitors. Biotechnology 199224 104-108.

24 Kimura S \& Ikeda-Saito M. Human myeloperoxidase and thyroid peroxidase, two enzymes with separate and distinct physiological functions, are evolutionary related members of the same family. Proteins 19883 113-120.

25 Bikker H, Baas F \& de Vijlder JJM. Molecular analysis of mutated thyroid peroxidase detected in patients with total iodide organification defects. Journal of Clinical Endocrinology and Metabolism 199782 649-653.

26 Zeng J \& Fenna RE. X ray crystal structure of canine myeloperoxidase at $3 \AA$ resolution. Journal of Molecular Biology 1992226 185-207.

Received 21 December 2000

Accepted 15 March 2001 